\title{
Decreased Response of Human Milk Leukocytes to Chemoattractant Peptides ${ }^{1}$
}

\author{
LARRY W. THORPE, H. ELIZABETH RUDLOFF, LESLIE C. POWELL, AND \\ ARMOND S. GOLDMAN \\ Departments of Pediatrics [H.E.R., A.S.G.], Obstetrics and Gynecology [L.C.P.], and Human Biological \\ Chemistry and Genetics [L.W.T., A.S.G.], The University of Texas Medical Branch, Galveston, \\ Texas $77550-2776$
}

\begin{abstract}
To test the hypothesis that neutrophils and macrophages in human milk may not defend by classical inflammatory mechanisms, experiments were conducted to ascertain whether adherence, orientation, and directed motility of these leukocytes would be enhanced by exposure to chemoattractant peptides including $\mathrm{N}$-formyl-L-methionyl-L-phenylalanine and $\mathrm{N}$-formyl-L-methionyl-L-leucyl$\mathrm{L}$-phenylalanine and $\mathrm{C} 5 \mathrm{a}$ generated from zymosan activated human serum. Adherence and spatial orientation were tested on coverglasses and in Zigmond chambers, and chemotaxis was examined by Boyden chambers and a subagarose technique. Whereas, the adherence, orientation, and directed movement of adult peripheral blood neutrophils and monocytes were significantly enhanced by those chemotactic agents, human milk leukocytes failed to respond. The failure of the response of human milk leukocytes was not due to alterations in maternal peripheral blood leukocytes but appeared to be due partially to inhibitors in human milk. The experiments suggest that human milk leukocytes may be modified in the mammary gland to protect by noninflammatory mechanisms. (Pediatr Res 20: 373-377, 1986)
\end{abstract}

\section{Abbreviations}

HMLs, human milk leukocytes

PBLs, peripheral blood leukocytes

HBSS, Hanks' balanced salt solution

MEM, minimal essential media

F-Met-Leu-Phe, N-formyl-L-methionyl-L-leucyl-L-phenylalanine

F-Met-Phe, N-formyl-L-methionyl-L-phenylalanine

ZAS, zymosan activated human serum

There is considerable evidence that breast-fed infants, particularly in underdeveloped countries, are protected against gastrointestinal pathogens (for review, see References 1-3). The manner in which this protection occurs is not known despite a host of descriptive studies of the immunologic system in human milk. Epidemiologic investigations suggest, however, that the protection may not depend upon the induction of inflammation by host resistance factors in human milk. For example, when infants from rural Central America received human milk natu-

Received July 2, 1985; accepted December 2, 1985

Correspondence should be addressed to Dr. Armond S. Goldman, Department of Pediatrics, University of Texas Medical Branch, Galveston, TX 77550-2776.

This work was supported in part by a contract from the Department of Health and Human Services, National Institutes of Health, No. 1 HD 22814.

${ }^{1}$ This work was present in part at the 1985 meetings of the Society for Pediatric Research and the American Pediatric Society. rally contaminated with bacterial pathogens such as Shigella (4, $5)$, they failed to display clinical features of gastroenteritis including abdominal pain, vomiting, diarrhea, or gross melena.

This seemed paradoxical since neutrophils and macrophages that cause inflammatory reactions are found in human milk. These leukocytes in human milk, however, display unusual morphology (6-14) including many lipid-filled vacuoles, milk fat globules, and casein micelles. Because of those unusual features and the suggestive clinical evidence that certain enteric pathogens may not evoke an inflammatory response in breastfed infants, we hypothesized that HMLs may not protect the recipient by mechanisms that are expected from PBLs. For instance, if they fail to recognize or respond to chemoattractant agents, then they may be unable to adhere to or migrate into the intestinal mucosa of the infant. Consequently, they would not generate a local inflammatory response that would injure those tissues. To test that hypothesis, we first examined whether HMLs respond to chemotactic peptides by increasing their adherence, orientation, and directed movement.

\section{MATERIALS AND METHODS}

Subject selection; collection-preparation of leukocytes. The use of human subjects in this research was approved by the institutional review board of the medical school. The donors were healthy women age $20-34$ yr who had delivered full term healthy infants vaginally 2-3 days before the collections (15). Milk was collected into polypropylene tubes by a low pressure electric pump (Egnell, Inc., Cary, IL). Heparinized venous blood was collected from healthy adult males, healthy nonpregnant adult females, or healthy women in the first two postpartum days.

Human milk leukocytes were prepared by the following procedure. The cells were washed three times in HBSS and resuspended in MEM (Flow Laboratories, McLean, VA) to achieve a final concentration of $1 \times 10^{6}$ cells $/ \mathrm{ml}$. Only unfractionated HMLs were used in the experiments. To ascertain whether both neutrophils and macrophages were present, aliquots of preparations were examined for nonspecific esterase positive cells (macrophages) and negative cells (neutrophils) $(15,16)$. The proportions of neutrophils and macrophages appeared to be typical of early human milk secretions, e.g. 45-55\% neutrophils and 40$50 \%$ macrophages.

PBLs were prepared from venous blood by sedimentation with $6 \%$ dextran (17). Remaining erythrocytes were lysed with hypotonic saline. No further cellular fractionation was carried out. The blood leukocytes were washed three times in HBSS and resuspended in MEM to achieve a final concentration of $1 \times 10^{6}$ cells/ml.

Adherence-orientation of cells. The abilities of HMLs or PBLs to adhere and orient in the presence of chemoattractant peptides were measured by two methods. The concentrations of HMLs 
or PBLs suspended in MEM containing $10 \%$ fetal calf serum (Biofluids, Rockville, MD) were adjusted to $1 \times 10^{6}$ cells $/ \mathrm{ml}$. One hundred $\mu$ l of each suspension of HMLs or PBLs were mixed with $100 \mu$ l of a $10^{-9} \mathrm{M}$ solution of F-Met-Leu-Phe (Sigma Chemical Co., St. Louis, MO) and examined immediately on coverglasses by phase contrast microscopy $(630 \times)$.

Orientation of the leukocytes to F-Met-Leu-Phe $\left(10^{-9} \mathrm{M}\right.$ concentration) was evaluated by the use of in vitro chambers as described by Zigmond (18, 19). Approximately $100 \mu \mathrm{l}$ of an unfractionated washed suspension containing $1-2 \times 10^{6}$ cells/ $\mathrm{ml}$ were streaked across the center of a glass coverslip. After the cells settled on the surface of the coverslip and the excess MEM drained off, the coverslip was inverted over the chamber slide and fixed in place by brass clips. One well was filled with MEM; immediately thereafter, the other was filled with the F-Met-LeuPhe. The slide was then examined by phase microscopy $(630 \times)$.

Adherence was quantitated microscopically by counting the number of adherent and nonadherent cells in 10 random fields. Similarly, the degree of orientation of the leukocytes in Zigmond chambers was assessed by counting the number of cells in 10 high power fields on each slide which remained rounded or became polarized toward the chemotactic gradient. The results were expressed as a percentage of oriented cells.

Chemotaxis under agarose. Leukocyte migration under agarose was performed as reported by Nelson et al. (20, 21). Three different chemotaxins were utilized in these experiments. F-MetPhe (Sigma; $\left.10^{-6}-10^{-9} \mathrm{M}\right)$ and F-Met-Leu-Phe $\left(10^{-6}-10^{-9} \mathrm{M}\right)$ were prepared in MEM. A preparation of $\mathrm{C} 5 \mathrm{a}$ was made by reacting $5 \mathrm{mg}$ of zymosan (Sigma) with $20 \%$ normal human serum in MEM. The optimal concentrations of the chemoattractant agents used in these experiments were determined in prior experiments with PBLs (data not shown) and were similar or identical to the optimal doses of these chemoattractants found in previously reported studies. The possibility that early milk (colostrum) contained preformed chemotactic factors was tested by using whole colostrum, a $50 \%$ concentration of whole colostrum, a $10 \%$ concentration of the aqueous phase of colostrum or a preparation of washed colostral leukocytes as potential chemotaxins for PBLs. The concentrations of responding cells, i.e. PBLs or HMLs, were adjusted to $0.4-1.0 \times 10^{6}$ cells $/ 10 \mu \mathrm{l}$ in MEM. Ten $\mu$ lof the chemotaxin were placed into the outer wells and $10 \mu \mathrm{l}$ of the responding cells (PBLs or HMLs) in the inner wells. The chemotactic preparations were incubated in a $\mathrm{CO}_{2}$ incubator at $37^{\circ} \mathrm{C}$ for 2 and $20 \mathrm{~h}$. Cellular migration was then assessed microscopically by measuring the distance from the edge of the cell well to the leading front of cells facing toward or $180^{\circ}$ away from the chemotaxin well. The measurements were checked in a blinded fashion by two of the investigators. Their observations agreed with those of the observer who knew the source of the leukocytes.

Chemotaxis in Boyden chambers. The Boyden chamber method was modified from the original technique (22) in the following ways. Cellulose nitrate filters $(3 \mu$ pore size for PBLs; $5 \mu$ pore size for HMLs; Millipore Filter Corp, Bedford, MA) were used. The concentration of either HMLs or PBLs was adjusted to $1 \times 10^{6} / \mathrm{ml}$ in MEM and $1 \mathrm{ml}$ of each cell preparation was placed in the upper chamber. F-Met-Leu-Phe $\left(10^{-9} \mathrm{M}\right.$ in MEM) or ZAS was placed into the lower chamber until the fluid levels of the two chambers were equal. The chambers were capped and incubated in a $\mathrm{CO}_{2}$ incubator for $3 \mathrm{~h}$. Migration was assessed by a modification of the leading edge method reported by Zigmond and Hirsch (23). The measurements were checked in a blinded fashion by two of the investigators. Their observations agreed with those of the observer who knew the source of the leukocytes.

Effects of colostrum upon PBLs. A series of experiments was conducted to test if colostrum inhibited the response of HMLs to chemoattractants. Fresh, whole human colostrum and a cellfree preparation of colostrum (aqueous phase) were used in these experiments. The aqueous phase was prepared by centrifuging human colostrum repeatedly until the preparation was cell-free by microscopic examination. The effect of the aqueous phase upon the adherence and orientation of human PBLs was assessed in the following manner. Peripheral blood leukocytes $(1-2 \times$ $10^{6} / \mathrm{ml}$ ) suspended in the aqueous phase of colostrum were incubated for $1 \mathrm{~h}$ at $22^{\circ} \mathrm{C}$ and then placed on coverglasses which were mounted on depression slides. One hundred $\mu \mathrm{l}$ of this suspension (i.e. $1-2 \times 10^{5}$ cells) were mixed with a $10^{-9} \mathrm{M}$ solution of F-Met-Leu-Phe and examined for adherence and orientation as previously described. The remaining PBLs suspended in the aqueous phase of colostrum were washed twice, resuspended in MEM containing 10\% fetal calf serum and incubated for another hour at room temperature. Following this incubation, $100 \mu \mathrm{l}$ of the cells were again tested for adherence and orientation as previously described.

The effect of colostrum upon the motility of human PBLs was examined. PBLs were preincubated in whole colostrum or the aqueous phase of colostrum for $60 \mathrm{~min}$ at $22^{\circ} \mathrm{C}$ and either washed with HBSS or not washed. The movement of PBLs toward F-Met-Leu-Phe was then quantified as previously described and compared to the movement of PBLs not exposed to human colostrum.

Statistical analysis. An unpaired Student's $t$ test was used to compare the responses of HMLs and PBLs to chemoattractants, whereas a paired Student's $t$ test was used to test the effect of colostrum upon the response of PBLs to $\mathrm{N}$-formylmethionyl peptides.

\section{RESULTS}

Adherence. HMLs and PBLs from two groups each consisting of five individuals, were used in these experiments. Few fresh HMLs adhered to the coverglasses of the Zigmond chamber in the absence or presence of F-Met-Leu-Phe (Figs. 1 $A$ and 2). Those HMLs that were adherent remained in a round configuration and did not spread (Fig. $1 A$ ). In contrast, many PBLs suspended in MEM were adherent (Figs. $1 B$ and 2) and spread quickly following stimulation with F-Met-Leu-Phe (Fig. $1 B$ ).

Orientation. HMLs and PBLs from two groups, each consisting of five individuals, were used in these experiments. HMLs failed to orient toward chemotactic gradients of $\mathrm{N}$-formylmethionyl peptides or ZAS (Figs. 2 and $3 A$ ), whereas the majority of adherent PBLs oriented toward the chemotactic gradient (Figs. 2 and $3 B$ ). The lack of orientation of HMLs toward chemotaxins was also observed with nonadherent HMLs in Zigmond chambers and when they were tested by the subagarose technique (see next section).

Chemotaxis. There were remarkable differences between the migration of human PBLs and HMLs in response to chemotactic agents. In six separate experiments utilizing the subagarose method, virtually no movement of HMLs was found in the first $2 \mathrm{~h}$, whereas PBLs consistently displayed a chemotactic response within 2 h (Fig. 4). By 24 h, random movement of some human milk lymphocytes and macrophages was observed (data not presented), but no chemotactic response was found. Neither whole colostrum, a $50 \%$ concentration of whole colostrum, a $10 \%$ concentration of aqueous colostrum, nor colostral cells were found to be chemotactic. Those data were therefore pooled for presentation (Fig. 4).

In the Boyden chamber experiments, virtually no neutrophils or macrophages in human milk moved in response to chemotactic factors (Table 1), although some human milk lymphocytes did so (data not presented). In addition, no directed movement of HMLs could be detected when substantially higher or lower doses of these chemoattractant agents were used (data not presented)

Behavior of maternal leukocytes. Because of the failure of HMLs to respond to chemoattractants by increased adherence and directed movement, we questioned whether PBLs from women in the first 2 postpartum days would be similarly affected. 

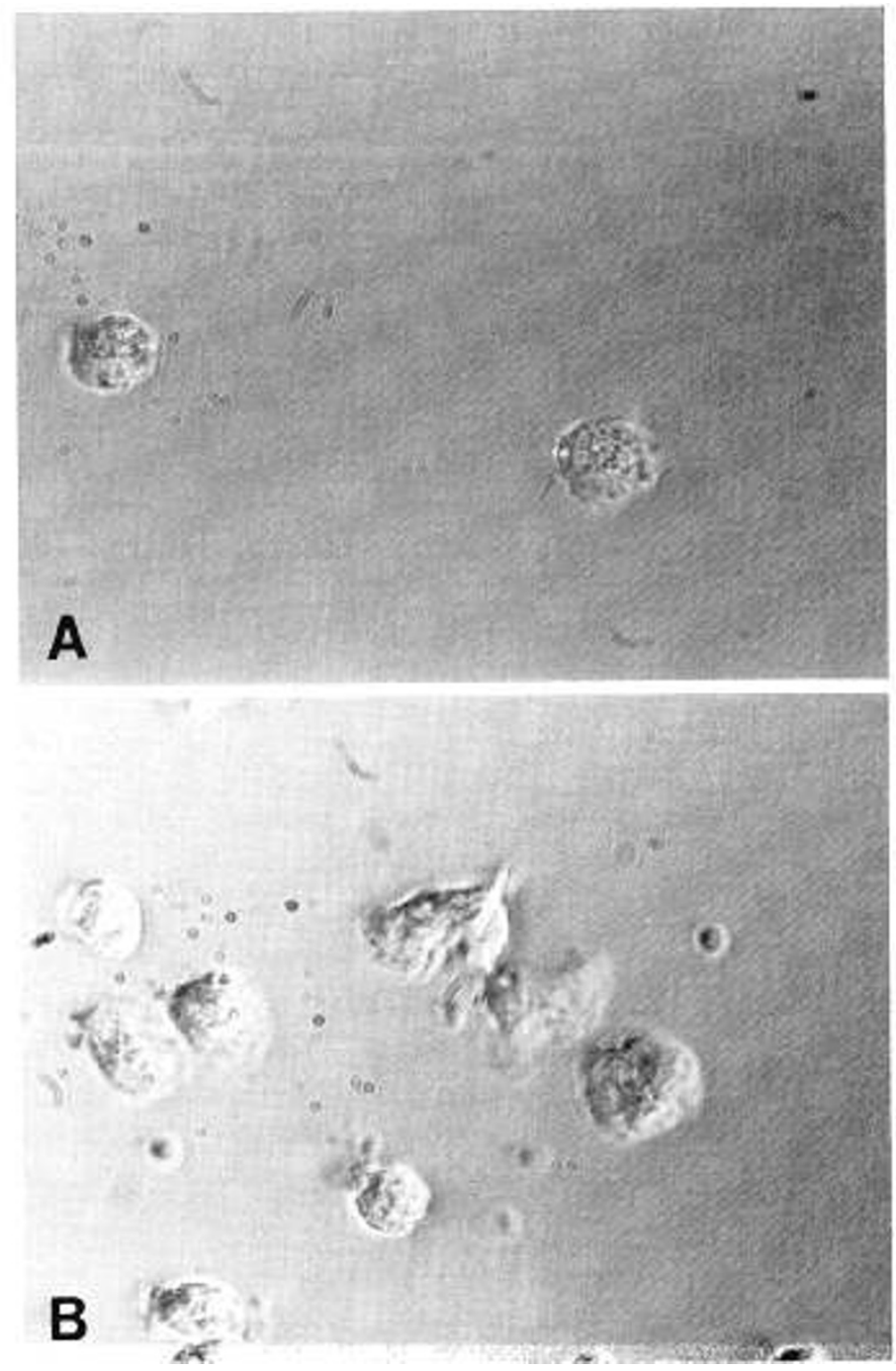

Fig. 1. Representative microphotograph $(1000 \times)$ of HMLs $(A)$ and PBLs $(B)$, exposed to F-Met-Leu-Phe. Few HMLs were adhered to the coverglasses, whereas many adherent PBLs were found.

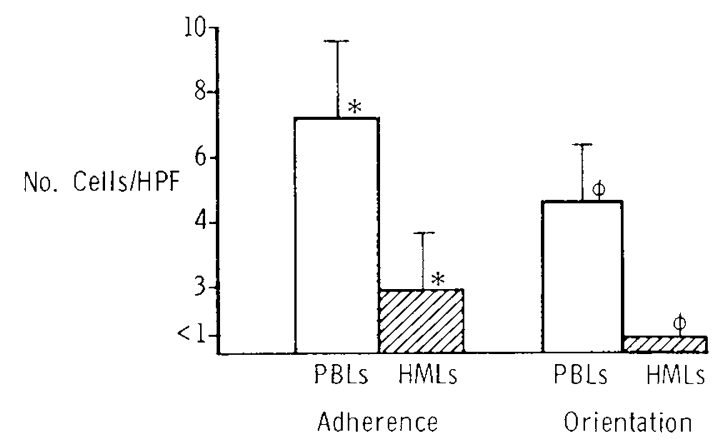

Fig. 2. Adherence and orientation of PBLs and HMLs after exposure to F-Mct-Lcu-Phe $\left(10^{-9} \mathrm{M}\right)$. Data from five separate experiments are presented as the mean \pm SD of leukocytes adherent to coverglasses after exposure to F-Met-Leu-Phe and cells oriented toward the chemoattractant. The abilities of HMLs to adhere and orient in response to F-MetLeu-Phe were significantly decreased (symbols indicate $p<0.001)$.

The adherence and directed movement of maternal PBLs following exposure to F-Met-Leu-Phe or ZAS were, however, indistinguishable from nonmaternal adult neutrophils (Table 2). In addition, the random movements of maternal and nonmaternal adult blood neutrophils were similar (data no shown).

Effects of colostrum on PBLs. The effect of human colostrum


Fig. 3. Representative photomicrographs $(1000 \times)$ of HMLs $(A)$ and PBLs $(B)$ exposed to a chemotactic gradient of F-Met-Leu-Phe. The source of the chemotaxin is at the top of each microscopic field. Virtually all PBLs oriented toward the gradient. whereas the HMLs did not.

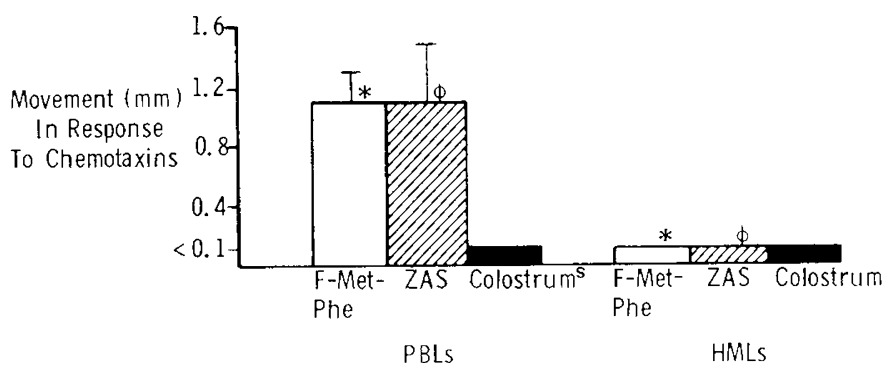

Fig. 4. Leukocyte chemotaxis under agarose. Data from six separate expcriments are presented as the distance of migration after $2 \mathrm{~h}$ of incubation of the cells toward the well containing the chemotaxin $(\mathrm{mm}$; mean \pm SD). The chemotactic responses of HMLs to F-Met-Phe and ZAS were reduced significantly $(p<0.001)$. There were no differences in the migration of PBLs and HMLs $180^{\circ}$ away from the chemotaxins (e.g. $<0.1 \mathrm{~mm}$; no data are presented). ${ }^{\mathrm{s}}$ Data were similar for cells and fluid phase. ${ }^{*} \phi$ The responses of HMLs to both chemotaxins were decreased $(p<0.001)$.

upon the adherence and directed movement of PBLs following exposure to F-Met-Leu-Phe are presented in Table 3. Five separate experiments were performed. The glass adherence of PBLs incubated in the aqueous phase of colostrum was greatly inhib- 
Table 1. Leukocyte chemotaxis in Boyden chambers*

\begin{tabular}{clcc}
\hline Cells & Chemotaxins & $\begin{array}{c}\text { Distance of } \\
\text { leading } \\
\text { edge }(\mu)\end{array}$ & $\begin{array}{c}\text { No. cells HPF } \\
\text { at leading } \\
\text { edge }\end{array}$ \\
\hline \multirow{2}{*}{ PBLs } & None & 21 & $>100 \dagger$ \\
& F-Met-Leu-Phe & 21 & $>100$ \\
& ZAS & 21 & $>100$ \\
HMLs & None & $5 \pm 5$ & $<1$ \\
& F-Met-Leu-Phe & $6 \pm 6$ & $1 \pm 1$ \\
& ZAS & $5 \pm 5$ & $1 \pm 1$ \\
\hline
\end{tabular}

* Data from four separate experiments are expressed as the mean \pm SD of the maximal distance $(\mu)$ of migration (leading edge) of the cells and the number of cells per HPF at the leading edge. The depth of each filter was $21 \mu$. In the case of PBLs, only the mean distance $(21 \mu)$ was therefore presented since the leading edge was the surface of the filter facing the chemotactic chamber in each case. The chemotactic responses of HMLs to F-Met-Leu-Phe and ZAS were greatly decreased $(p<0.001)$.

$\dagger$ Because the incubations were increased to $3 \mathrm{~h}$ to more completely test the movement of HMLs, the degree of random movement did not permit a true assessment of directed movement of the PBLs. Nevertheless, the inhibition of movement of HMLs was evident.

Table 2. Comparison of adherence to glass and chemotaxis under agarose of nonmaternal adult and maternal PBLs*

\begin{tabular}{ccccc}
\hline \multirow{2}{*}{ PBLs } & \multicolumn{2}{c}{ Adherence } & & \multicolumn{2}{c}{ Chemotaxis $(\mathrm{mm})$} \\
\cline { 2 - 3 } \cline { 5 - 5 } \cline { 5 - 5 } No. cells/HPF & & F-Met-Leu-Phe & ZAS \\
\hline Maternal & $7.2 \pm 2.3$ & & $1.1 \pm 0.2$ & $1.2 \pm 0.3$ \\
\hline
\end{tabular}

* The mean \pm SD of data from four separate experiments are presented. No differences were found between nonmaternal and maternal blood leukocytes (principally neutrophils).

Table 3. Effects of colostrum on glass adherence and movement of PBLs after exposure to F-Met-Leu-Phe*

\begin{tabular}{|c|c|c|c|}
\hline \multicolumn{2}{|c|}{ Experimental conditions } & \multirow{2}{*}{$\begin{array}{c}\text { Adherence } \\
\text { No. cells/HPF }\end{array}$} & \multirow{2}{*}{$\begin{array}{c}\begin{array}{c}\text { Chemotaxis } \\
(\mathrm{mm})\end{array} \\
\text { F-Met-Leu-Phe }\end{array}$} \\
\hline Media & Washing & & \\
\hline $\begin{array}{l}\text { Fetal calf serum-RPMI } \\
\text { Human colostrum }\end{array}$ & - & $7.8 \pm 2.7$ & $1.5 \pm 0.1$ \\
\hline Whole & - & Not done & $0.7 \pm 0.1$ \\
\hline & + & Not done & $0.6 \pm 0.6$ \\
\hline Aqueous phase & - & $1.5 \pm 0.8$ & $1.5 \pm 0.4$ \\
\hline & + & $10.0 \pm 2.8$ & $1.0 \pm 0.6$ \\
\hline
\end{tabular}

* Directed movement of adult (nonmaternal) PBLs under agarose was examined. The mean $\pm \mathrm{SD}$ of data from five separate experiments are presented. The inhibition of adherence induced by colostrum was reversed by washing $(p<0.001)$.

ited, but the inhibition was reversed by washing the colostrumtreated cells and reincubating them in tissue culture media containing fetal calf serum. The Zigmond chamber observations did not indicate that the orientation of adherent PBLs was inhibited by colostrum, but no data were presented because comparatively few adherent cells were found. No inhibition of chemotaxis was found with the aqueous phase. The effect of whole colostrum upon the chemotaxis of PBLs varied from complete inhibition with two specimens to marginal inhibition with three samples (Table 3).

\section{DISCUSSION}

In keeping with their unusual morphology, it appears from this study that certain functions of HMLs may be altered. Even though there are limitations in extrapolating from in vitro obser- vations to the in vivo state, it is clear that the neutrophils and macrophages from human milk do not respond to chemotactic agents that consistently affect their counterparts in peripheral blood. In that respect, the adherence, orientation, and directed movement of HMLs in response to zymosan-activated complement components (24) or $\mathrm{N}$-formylmethionyl peptides (25) were significantly decreased. These findings are in keeping with those of Khan et al. (26) who reported a limited chemotactic response of human colostral leukocytes to bacterial products in Boyden chambers. However, our studies were more complete since we used filters with a larger pore size to accomodate the comparatively large human milk leukocytes, a second method was used to quantitate chemotaxis (the subagarose technique), chemoattractants of human as well as bacterial origin were used, and adherence and orientation were directly examined. Recently, Hawes and Jones (27) reported that cells from human milk did not migrate through 5 or $8 \mu \mathrm{m}$ pore size filters in a random manner or in response to casein. No other chemoattractant agents or chemotactic assays were used and adherence and orientation of HMLs were not examined. Nevertheless, their data are consistent with the findings from the present study.

In subsequent experiments, we investigated the cause of the lack of response of HMLs to those agents. To begin with, we tested whether PBLs from women in the immediate postpartum period were similarly inhibited. The adherence and directed movement of maternal blood leukocytes (principally neutrophils) following exposure to the chemotactic agents increased significantly and those findings were in keeping with the thesis that those functions are necessary for blood leukocytes to traverse the mammary gland epithelium and hence become constituents of human milk.

Because of the decreased ability of HMLs to respond to chemoattractants, we questioned whether the cells were inhibited by constituents in human milk. In addition to fresh whole colostrum, an aqueous phase of colostrum prepared by low speed centrifugation was tested. The lipid phase per se was not used because the aggregated fat globules and other particles might have created an artificial physical barrier to the adherence or movement of the tested leukocytes. The nonaqueous phase was tested indirectly, however, by comparing the effects of fresh whole colostrum with the aqueous phase. The studies demonstrated that the adherence of HMLs was reversibly inhibited by the aqueous phase of milk, as we had suspected from a previous study (15). Chemotaxis of PBLs was not inhibited by the aqueous phase. In contrast, chemotaxis was inhibited by certain specimens of whole colostrum, presumably by the lipid phase. It did not appear that the decreased movement of the cells was due to chemotactic deactivation (28) since no preformed chemotactic activity was discernable. Those results were similar to those reported by Bjorksten et al. (29). Our results, however, may conflict with those of Hawes and Jones (27) who reported a slight but significant chemoattractant effect of human milk in their two chamber assays. Evidently, the effect of colostrum upon leukocytes is complex and the analysis of these effects is beyond the scope of this study. Nevertheless, our study suggest that certain factors in milk may be responsible in part for the failure of HMLs to respond to chemoattractants.

It is known that peripheral blood neutrophils and monocytes have discrete receptors for $\mathrm{N}$-formylmethionyl peptides and $\mathrm{C} 5 \mathrm{a}$ $(25,30-32)$ and that binding of these ligands to the receptors activates a train of events which lead to an enhancement of adherence, polarization, and directed movement. In that regard, a number of reports indicate that there are subpopulations of human neutrophils in respect to certain functional activities including the response to chemotactic agents (33-35). Moreover, it recently was demonstrated that subpopulations of blood neutrophils that respond most actively to chemotaxins bind more of the chemoattractant (F-Met-Leu-Phe), exhibit a depolarization of their membranes, and are able to displace the chemoattractant ligands from receptors more readily than subpopulations that 
respond less well to those agents (35). Thus, it is possible that HMLs may represent special subpopulations of PBLs. In addition, it is possible that surface membrane adherence glycoproteins $(36,37)$ or the cytoskeleton may be altered in HMLs. Studies of ligand binding, adherence proteins, and the cytoskeleton may therefore help to identify the mechanism of the diminished response of HMLs to chemoattractants.

Regardless of the exact change in these HMLs, it is likely that HMLs are modified when they pass through the mammary gland. Apparently, leukocytes in human milk are adapted not to adhere to epithelium of the ducts of the mammary gland and are thus free to be transferred to the infant via breast-feeding. Based upon these and previous studies, we postulate that HMLs may defend the nursing infant without injuring the mucosa of the alimentary tract of the recipient. The limited response of these cells to chemotactic agents also suggests that the action of these cells is relegated to the surface or the lumen of the alimentary tract. Such an hypothesis is particularly appealing in view of the recent report that human milk macrophages stimulated in vitro produce toxic oxygen compounds (38) which potentially could damage the epithelium of the aeroalimentary tract. Further studies will be required, however, to ascertain their in vivo fate and functions of HMLs in the recipient infant.

Acknowledgments. The authors acknowledge Susan Kovacevich and Sherry Lackey for their aid in the preparation of this manuscript.

\section{REFERENCES}

1. Goldman AS, Smith CW 1973 Host resistance factors in human milk. J Pediatr 82:1082-1090

2. Cunningham AS 1981 Breast-feeding and morbidity in industrialized countries: an update. In: Jelliffe DB, Jelliffe EFB (eds) Advances in International Maternal and Child Health. Oxford University Press, New York, pp 128 168

3. Goldman AS, Ham Pong AJ, Goldblum RM 1985 Host defenses: development and maternal contributions. Adv Pediatr 32:71-100

4. Mata LJ, Urrutia JJ, Gordon JE 1967 Diarrheal disease in a cohort of Guatemalan village children observed from birth to age two years. Trop Geogr Med 19:247-257

5. Wyatt R, Mata LJ 1969 Bacteria in colostrum and milk of Guatamalan Indian women. J Trop Pediatr 15:159-162

6. Smith CW, Goldman AS 1968 The cells of human colostrum. I. In vivo studies of morphology and functions. Pediatr Res 2:103-109

7. Smith CW, Goldman AS, Yates RG 1971 Interactions of lymphocytes and macrophages from human colostrum: electron microscopic studies of the interacting lymphocyte. Exp Cell Res 69:409-415

8. Crago SS, Prince SJ, Pretlow TG, McGhee JR, Mestecky J 1979 Human colostral cells. I. Separation and characterization. Clin Exp Immunol 38:585597

9. Ho FCS, Wong RLC, Lawton JWM 1979 Human colostral and breast milk cells. Acta Paediatr Scand 68:389-396

10. France GL, Marmer DJ, Steele RW 1980 Breast feeding and Salmonella infection. Am J Dis Child I34:147-152

11. Johnson DF, France GL, Marmer DJ, Stecle RW 1980 Bactericidal mechanisms of human breast milk leukocytes. Infect Immun 28:314-318

12. Pickering LK, Cleary TG, Kohl S, Getz S 1980 Polymorphonuclear leukocytes of human colostrum. I. Oxidative metabolism and kinetics of killing of radiolabeled Staphyloccus aureus. J Infect Dis 142:685-693

13. Kohl S, Pickering LK, Cleary TG, Steinmetz KD, Loo LS 1980 Human colostral cytotoxicity. II. Relative defects in colostral leukocyte cytotoxicity and inhibition of peripheral blood leukocyte cytotoxicity by colostrum. J
Infect Dis 142:884-891

14. Tsuda H, Dickey WD, Goldman AS 1984 Separation of human colostral macrophages and neutrophils on gelatin and collagen-serum substrata. Cell Struct Function 8:367-371

15. Goldblum RM, Garza C, Johnson CA, Nichols BL, Goldman AS 1981 Human milk banking. I. Effects of container upon immunologic factors in mature milk. Nutr Res 1:449-459

16. Yam LT, Li CY, Crosby WH 1971 Cytochemical identification of monocytes and granulocytes. Am J Clin Pathol 55:283-290

17. Boyum A 1968 Isolation of leukocytes from human blood. Methyl cellulose, dextran, and ficoll as erythrocyte-aggregating agents. Scand J Clin Lab Invest 21(suppl 97):31-50

18. Zigmond SH 1974 Mechanisms of sensing chemical gradients by polymorphonuclear leukocytes. Nature 249:450-452

19. Zigmond SH 1977 Ability of polymorphonuclear leukocytes to orient in gradients of chemotactic factors. J Cell Biol 75:606-616

20. Nelson RD, Quie PG, Simmons RL 1975 Chemotaxis under agarose: a new and simple method for measuring chemotaxis and spontaneous migration of human polymorphonuclear leukocytes and monocytes. J Immunol 115:1650-1656

21. Nelson RD, McCormack RT, Fiegel VD 1978 Chemotaxis of human leukocytes under agarose. In: Gallin JI, Quie PG (eds) Leukocyte Chemotaxis: Methods, Physiology, and Clinical Implications. Raven Press, New York, pp $25-42$

22. Boyden S 1962 The chemotactic effect of mixtures of antibody and antigen on polymorphonuclear leukocytes. J Exp Med 115:453-466

23. Zigmond SH, Hirsch JG 1973 Leukocyte locomotion and chemotaxis: New methods for evaluation and demonstration of cell-derived chemotactic factor J Exp Med 137:387-410

24. Ward PA, Cochrane CG, Muller-Eberhard HJ 1965 The role of serum complement in chemotaxis of leukocytes in vitro. J Exp Med 122:327-346

25. Schiffman E, Corcoran BA, Wahl SM $1975 \mathrm{~N}$-formylmethionyl peptides as chemoattractants for leukocytes. Proc Nat Acad Sci USA 72:1059-1062

26. Khan AJ, Rosenfeld W, Vadapalli M, Biagton J, Khan P, Huq A, Evans HE 1980 Chemotaxis and random migration of human milk cells. J Pediatr 96:879-882

27. Hawes CS, Jones WR 1985 Human milk cell migration and production of monocyte chemotactic factor: lack of activity. Pediatr Res 19:996-999

28. Patrick RA, Hollers JC, Liu DY, Giese BH, Smith CW 1980 Effects of human complement component 1 inactivator in neutrophil chemotaxis and chemotactic deactivation. Infect Immun 28:700-707

29. Bjorksten B, Gothefors L, Sidenvall R 1979 The effect of human colostrum on neutrophil function. Pediatr Res 13:737-741

30. Niedel J, Wilkinson S, Cuatrecasas P 1979 Receptor mediated uptake and degradation of ${ }^{125} \mathrm{l}$-chemotactic peptide by human neutrophils. J Biol Chem 254:10700-10706

31. Fletcher MP, Seligmann BE, Gallin JI Correlation of human neutrophil secretion chemoattractant receptor mobilization, and enhanced functional capacity. J Immunol 128:941-948

32. Sullivan SJ, Zigmond SH 1980 Chemotactic peptide receptor modulation in polymorphonuclear leukocytes. J Cell Biol 85:703-711

33. Kiempner MS, Gallin JI 1978 Separation and characterization of human neutrophil subpopulations. Blood 51:659-669

34. Harvath L, Leonard EJ 1982 Two neutrophil populations in human blood with different chemotactic activities: Separation and chemoattractant binding. Infect Immun 36:443 -449

35. Seligmann B, Chused TM, Gallin JI 1985 Differential binding of chemoattractant peptide to subpopulations of human neutrophils. J Immunol 133:26412646

36. Buchanan MR, Crowley CH, Rosin RE, Grimbrone MA, Jr, Babior BM 1982 Studies on the interactions between GP-180-deficient neutrephils and vascular endothelium. Blood 60:160-165

37. Anderson DC, Schmalstieg FC, Finegold MJ, Hughes BJ, Rothlein R, Miller KJ, Kohl S, Tosi MS, Jacobs RL, Waldrop TC, Goldman AS, Shearer WT, Springer TA 1985 Severe and moderate phenotypes of heritable MAC-1, LFA-1, p150,95 deficiency: Their quantative definition and relation to leukocyte dysfunction and clinical features. J Infect Dis 152:668-689

38. Tsuda H, Takeshige K, Shibata Y, Minakami S 1984 Oxygen metabolism of human colostral macrophages: Comparison with monocytes and polymorphonuclear leukocytes. J Biochem 95:1237-1245 